\title{
Zoonotic transmission of Chlamydia psittaci in a chicken and turkey hatchery
}

\begin{abstract}
Correspondence
Veerle Dickx

Veerle.Dickx@UGent.be
\end{abstract}

Received 19 January 2011

Accepted 3 March 2011

\author{
Veerle Dickx and Daisy Vanrompay
}

\author{
Department of Molecular Biotechnology, Faculty of Bioscience Engineering, Ghent University, \\ Ghent, Belgium
}

\begin{abstract}
Chlamydia psittaci is an obligately intracellular Gram-negative bacterium causing respiratory disease (chlamydiosis) or asymptomatic carriage in birds. C. psittaci is a zoonotic agent causing psittacosis or parrot fever in humans. Vertical and/or horizontal transmission via eggs might have serious repercussions on the C. psittaci infection status of poultry flocks and thus on zoonotic risk for all workers along the poultry supply chain. We therefore studied the presence of $C$. psittaci in a hatchery. In addition, we examined all $(n=4)$ employees of the hatchery to evaluate the zoonotic risk. We could not detect C. psittaci on either eggshells or eggshell membranes. However, C. psittaci isolates of different outer-membrane protein $\mathrm{A}(\mathrm{ompA})$ genotypes were cultured from the air of both turkey (genotypes A and $C$ ) and chicken (genotype D) hatching chambers.

Zoonotic transmission occurred in all employees and a mixed infection with up to three different genotypes (A, D and C), also found in air samples, was discovered. Diagnostic monitoring and reporting of $C$. psittaci infections in poultry workers should be promoted. Additionally, an efficient veterinary vaccine and information campaigns on zoonotic risk and preventive measures against C. psittaci transmission would be beneficial to public health.
\end{abstract}

\section{INTRODUCTION}

Chlamydia psittaci is an obligately intracellular Gramnegative bacterium causing respiratory disease (chlamydiosis) or asymptomatic carriage in birds (Vanrompay et al., 1995a). It is a zoonotic agent causing psittacosis in humans. Zoonotic transfer occurs through inhalation of contaminated dust particles or contaminated aerosols created from nasal and/or eye secretions or from dried faeces (Beeckman \& Vanrompay, 2009). In humans, symptoms may include high fever accompanied by a relatively low pulse, chills, headache, myalgia, nonproductive coughing and difficulty breathing. The incubation period is 5-14 days. The disease is rarely fatal in properly treated patients.

C. psittaci infections are almost endemic in poultry (Laroucau et al., 2009b; Sting et al., 2006; Van Loock et al., 2005a; Verminnen et al., 2006) and zoonotic transfer of C. psittaci is a threat to poultry workers all over the world (Chahota et al., 2000; Dickx et al., 2010; Gaede et al., 2008; Laroucau et al., 2009a; Verminnen et al., 2008).

Vertical or transovarial transmission of $C$. psittaci during formation of the egg in the ovary/oviduct of the breeder has been described for chicken (Wittenbrink et al., 1993) and turkey (Lublin et al., 1996) eggs. It leads to infection of 1-day-old birds. Nevertheless, vertical transmission of C. psittaci is thought to be rare (Harkinezhad et al., 2009). Thus, it might not be the main origin of infection for 1-day-old birds. As far as we know, horizontal infection of embryos or other egg contents by eggshell penetrating of C. psittaci has not been examined. Faecal contamination of eggshells by infected hens or during egg passage in the cloaca might occur, as C. psittaci resides in the gut and is excreted through the faeces (Harkinezhad et al., 2009). C. psittaci (diameter $0.2 \mu \mathrm{m}$ ) is very small compared to the well-known faecal egg contaminant Salmonella (diameter $0.7-1.5 \mu \mathrm{m}$, length $2-5 \mu \mathrm{m}$ ). Thus, $C$. psittaci could be even more easily internalized in eggs.

Vertical and/or horizontal transfer might have repercussions on the C. psittaci infection status of poultry flocks and thus on zoonotic risk for all workers along the poultry supply chain. We therefore studied the presence of C. psittaci in a hatchery. Additionally, we examined all employees of the hatchery to evaluate the zoonotic risk.

\section{METHODS}

Background. The study was conducted in a Belgian hatchery located in West Flanders. The hatchery had two hatching facilities in separate corridors: one used for both turkey and guinea fowl eggs and the other used solely for hatching chicken eggs. The hatchery was selected based on the willingness to participate in this study.

In June and September 2010, we performed a C. psittaci study in the turkey/guinea fowl and chicken hatching facilities, respectively. Eggshells and eggshell membranes were sampled. Additionally, C. psittaci bioaerosol monitoring was performed, sampling air from the turkey/guinea fowl or chicken hatching chambers. The employees, two men (M1 and M2) and two women (F1 and F2), having daily 
contact with eggs and hatchlings, voluntarily participated (informed consent) in this study and provided us with a self-taken pharyngeal swab for chlamydial diagnosis.

Sampling details and processing of samples prior to analyses. During the study in the turkey/guinea fowl and chicken facilities, at the beginning (T0), two subsequent air samples were taken from a cleaned, disinfected (formaldehyde fumigation) hatching chamber (17.12 $\mathrm{m}^{3}$; P13 Petersime, Zulte, Belgium), subsequently to be used for turkey or chicken eggs. Next, 26-day-old or 19-day-old embryonated turkey or chicken eggs, respectively, were brought in the hatching room, fumigated with formaldehyde and incubated under hatching conditions (turkey eggs, $37.4{ }^{\circ} \mathrm{C}$ and $90 \%$ relative humidity; chicken eggs, $37{ }^{\circ} \mathrm{C}$ and $90 \%$ relative humidity). Two days later, the hatching process started. Two subsequent air samples were taken at several time points during this hatching process: (i) in the morning when only a few animals (10\%) had hatched (T1); (ii) at noon (T2); and (iii) in the evening when most animals (90\%) had hatched (T3). Bioaerosol monitoring was performed using the MAS100 Eco Sampler (Merck) together with the in-house-designed air collection medium ChlamyTrap at an air flow rate of $1001 \mathrm{~min}^{-1}$ for 10 min (Van Droogenbroeck et al., 2009a). At each time point, two samples were taken. After air sampling, Petri dishes with $20 \mathrm{ml}$ ChlamyTrap were transported on ice and stored at $-80{ }^{\circ} \mathrm{C}$ until tested. Samples taken at the same time were pooled for further processing. Next, $40 \mathrm{ml}$ of the pooled air collection medium was divided in two equal parts. All samples were ultracentrifuged $\left(45000 \mathrm{~g}, 45 \mathrm{~min}, 4{ }^{\circ} \mathrm{C}\right)$. Pellets for culture were suspended in $500 \mu$ l chlamydia transport medium (Vanrompay et al., 1992) while those for C. psittaci genotyping were suspended in $198 \mu \mathrm{l}$ DNA extraction buffer (Van Loock et al., 2005b). Samples were stored at $-80{ }^{\circ} \mathrm{C}$ until tested.

Rayon-tipped aluminium-shafted swabs (Copan; Fiers) were used to sample in twofold the employees, the eggshell of 20 randomly selected turkey $(0.15 \%)$ or chicken $(0.10 \%)$ eggs before hatching as well as the eggshell membranes of 20 additional, randomly selected turkey $(0.15 \%)$ or chicken $(0.10 \%)$ eggs after hatching. Eggs in a hatching room came from the same batch and one single parental flock. Swabs for chlamydial culture contained chlamydia transport medium, while dry swabs were used for C. psittaci genotyping. Swabs were transported on ice and stored at $-80{ }^{\circ} \mathrm{C}$ until processed.

C. psittaci culture. The presence of viable C. psittaci in air samples or swabs was examined by bacterial culture in Buffalo Green Monkey (BGM) cells identifying C. psittaci by use of direct immunofluorescence staining at day 6 post-inoculation (IMAGEN; Oxoid) (Vanrompay et al., 1994). The number of C. psittaci-positive cells was counted in five randomly selected microscopic fields $(\times 600$; Nikon Eclipse TE2000-E). A score from 0 to 4 was given. Score 0 indicated the absence of $C$. psittaci. Score 1 was given when a mean of 1-5 non-replicating elementary bodies were present. Scores 2, 3 and 4 were given when a mean of $1-5,6-10$ and $>10$ inclusion-positive cells could be observed (Vanrompay et al., 1994). Subsequently, C. psittaci in positive samples was titrated according to the method of Spearman and Kaerber determining the $\log _{10} 50 \%$ tissue culture infective dose $\left(\mathrm{TCID}_{50}\right)$ per $\mathrm{ml}$ chlamydia transport medium or per ml ChlamyTrap air collection medium (Mayr et al., 1974).

C. psittaci genotyping. For all samples, DNA extraction was performed as previously described. Outer-membrane protein A (ompA) genotyping was performed by a C. psittaci genotype-specific real-time PCR (Geens et al., 2005). The test is based on using genotype-specific primers and genotype-specific TaqMan probes. Real-time PCR allowed molecular characterization of the C. psittaci strains involved, as well as quantification of chlamydial DNA using the human $\beta$-actin housekeeping gene for normalization (Van Droogenbroeck et al., 2009b).

\section{RESULTS AND DISCUSSION}

The results on bioaerosol monitoring and on the examination of human swabs are presented in Tables 1 and 2, respectively. C. psittaci was cultured from the air of both the turkey/guinea fowl and chicken hatching chambers and in both cases high titres of live organisms [up to $10^{10.75}$ (ml ChlamyTrap) ${ }^{-1}$ for the turkey hatching chamber; up to $10^{6.25}$ (ml ChlamyTrap) ${ }^{-1}$ for the chicken hatching chamber] were present in the air. Viable $C$. psittaci was present in hatching chambers from the start to the end of the hatching process (Table 1). Moreover, the microorganism was even there before the hatching process started, in cleaned, disinfected hatching rooms. C. psittaci titres in air increased 100 to 10000 times during the hatching process of chickens or turkeys, respectively.

The hatching chamber for chickens contained C. psittaci ompA genotype $\mathrm{D}$ at all examined time points. Recently, Dickx et al. (2010) also found genotype D in chickens being processed in an abattoir as well as in the air of the abattoir. Genotype D is considered highly virulent and is excreted extensively (Vanrompay et al., 1995b). The empty hatching chamber for turkey/guinea fowl eggs contained genotype C, and during hatching of turkeys, genotype A was found (Table 1). Thus, cleaning and disinfection (formaldehyde fumigation) of both hatching chambers after the previous egg incubation period was not sufficient to remove C. psittaci, as viable C. psittaci was still present in air samples taken at T0. Interestingly, guinea fowl eggs from France were incubated during the previous incubation period. C. psittaci has recently been detected by PCR in commercially raised guinea fowl in France. However, ompA genotyping failed (Laroucau et al., 2009b). Genotype C is mostly found in ducks and geese and has been

Table 1. Presence of C. psittaci in air samples from the turkey/ guinea fowl or chicken hatching chambers

\begin{tabular}{|lccc|}
\hline Time point & Culture score & $\begin{array}{c}\text { Titre }\left(\mathbf{l o g}_{\mathbf{1 0}}\right. \\
\left.\text { TCID }_{\mathbf{5 0}} \mathbf{~ m}^{\mathbf{- 1}}\right)\end{array}$ & $\begin{array}{c}\text { ompA } \\
\text { genotype }\end{array}$ \\
\hline $\begin{array}{l}\text { Turkey/guinea fowl } \\
\text { hatching chamber }\end{array}$ & & & \\
T0 & 4 & 6.75 & $\mathrm{C}$ \\
T1 & 4 & 6 & $\mathrm{~A}$ \\
T2 & 4 & 9 & $\mathrm{~A}$ \\
T3 & 4 & 10.75 & $\mathrm{~A}$ \\
Chicken hatching & & & \\
chamber & & & \\
T0 & 4 & 4.25 & $\mathrm{D}$ \\
T1 & 4 & 5.75 & $\mathrm{D}$ \\
T2 & 4 & 5.75 & $\mathrm{D}$ \\
T3 & 4 & 6.25 & $\mathrm{D}$ \\
& & & \\
\hline
\end{tabular}


isolated from poultry workers with respiratory disease (Harkinezhad et al., 2009).

Fumigation of eggs upon arrival in the hatching chamber seemed to have an effect on the amount of live organisms in the air, as genotype $\mathrm{C}$ was no longer detected at $\mathrm{T} 1$. Instead, genotype A was present, originating from turkey eggs. Genotype A has been isolated previously from turkeys (Van Loock et al., 2005a; Verminnen et al., 2008) and is highly virulent.

Eggshells were negative by both PCR and culture. Thus, contamination of eggs by secretions/excretions of the breeders was undetectable. Perhaps this was because only a small percentage of the eggs were sampled. However, this could also be due to the egg washing procedure performed in the hatchery upon arrival of the eggs and/or to fumigation of the eggs after being placed in the hatching chamber. On the other hand, C. psittaci, which is an extremely small bacterium, might rapidly penetrate the eggshell during cooling of freshly laid eggs in the breeder farm. Thus, in the future, eggshell contamination should be examined in the breeding facility instead of in a hatchery, using freshly laid eggs.

C. psittaci was not detected by either PCR or culture on eggshell membranes. Again, this could be because (i) only a small percentage of the eggs were examined or (ii) the organism was present in the animal itself, in the amnion or allantoic fluid and/or in the yolk, the yolk-sac membrane and/or the egg white. Perhaps the egg white, yolk sac and/ or yolk sac membrane become infected during artificial insemination with C. psittaci contaminated sperm or during formation of the egg in the ovary/oviduct. This could lead to the transfer of C. psittaci from the egg white and/or yolk to the embryo where the organisms might stay as aberrant temporary non-reproductive bodies, otherwise the embryo would die, in cells of the intestine and/or liver. Moreover, transovarian transmission through haematogenous spread of $C$. psittaci might also occur (Vanrompay et al., 1995b). Sampling egg contents and internal organs of embryos to monitor C. psittaci dissemination during the embryonic period could provide answers.

Nevertheless, vertical or horizontal egg contamination might be reduced by vaccinating hens and roosters on the breeder farms. However, $C$. psittaci vaccines are not available. Thus, prophylactic measures such as monitoring C. psittaci infections in breeders, optimal hygiene and disinfection of eggs soon after laying (Cox et al., 2000) are currently the main weapons against egg contamination.

All employees $(n=4)$ were C. psittaci-positive by culture, and mixed infections with up to three different ompA genotypes (A, C and D) were discovered. Previously, Van Droogenbroeck et al. (2009b) described a mixed C. psittaci genotype $\mathrm{D}, \mathrm{F}$ and $\mathrm{E} / \mathrm{B}$ asymptomatic infection in a veterinary surgeon. The infection originated from diseased industrial turkeys. Interestingly, the currently examined employees were also healthy. All employees had been working in the hatching facility for more than 20 years. In the past, they all had to seek medical attention because of respiratory disease and were treated with tetracylines without an aetiological diagnosis being performed. Thus, we cannot comment on a possible link with $C$. psittaci infections. However, as suggested by Dickx et al. (2010), poultry workers are almost continuously exposed to $C$. psittaci and therefore could have natural immunity against disease.

Genotype A was the most prevalent genotype in the employees, as shown by quantitative real-time PCR (Table 2). This is in accordance with the high prevalence of this genotype in air samples (Table 1). Men were less infected than women. The men spend most of their daytime in the administrative office and only assisted in the hatching chambers during 'peak moments'. The women spend most of their daytime handling both eggs and hatchlings.

Psittacosis is recognized as an occupational disease in the USA, Belgium, France, the Netherlands, Germany, Slovakia and the UK. In these countries, the occupational physician is obliged to report each case of psittacosis. In Belgium, there is a Fund for Occupational Diseases to assess C. psittaci cases and possibly accept them as an occupational disease, and take care of financial compensations for the employee if necessary.

Each employer is responsible for the health and safety of his employees and should focus on prevention of infections. Adequate prevention starts with a risk assessment. The employer, assisted by the occupational physician and occupational hygienist, evaluates the exposure to biological agents, taking into account the nature (contact with people or animals, or the workplace itself), intensity (the amount of infectious material handled) and duration of the worker's exposure (HSE, 2010). The risk assessment must also identify workers and other people who may not be in the workplace all the time (cleaners, maintenance and repair workers, contractors, students on placements) and members of the public who might be present (visitors) (HSE, 2010). Based on this information, adequate

Table 2. Normalized number of C. psittaci ompA copies per $5 \mu \mathrm{l}$ DNA extract determined by genotype-specific real-time PCR

The number of human $\beta$-actin copies in the reaction was determined in order to correct for inter-sample variability due to differences in sample taking and efficiency of DNA extraction. Absolute C. psittaci copy numbers were then normalized to the number of human $\beta$-actin gene copies in each sample.

\begin{tabular}{|lccc|}
\hline Pharyngeal sample & Genotype A & Genotype D & Genotype C \\
\hline M1 & $3.12 \times 10^{4}$ & $1.66 \times 10^{2}$ & Neg. \\
M2 & $1.55 \times 10^{3}$ & $1.34 \times 10^{2}$ & Neg. \\
F1 & $3.60 \times 10^{6}$ & $3.60 \times 10^{5}$ & $1.23 \times 10^{2}$ \\
F2 & $4.12 \times 10^{6}$ & $4.60 \times 10^{5}$ & $2.69 \times 10^{5}$ \\
\hline
\end{tabular}


preventive measures can be designed. The second phase is the implementation of the preventive measures. At this stage, education and training of the employees is very important to ensure that the measures are well understood and executed. When present, a company doctor might play a crucial role in both prevention and recognition of C. psittaci infections.

On a personal level, prevention includes a good hand hygiene protocol, protective clothing that does not retain dust and a mouth and eye (full face) mask. It is necessary to have a transition room where protective clothing may be kept. Employees should only stay in the hatching chambers for as short a time as possible. Good environmental hygiene is also important, such as daily cleaning and disinfection of work areas and equipment, hereby preventing the creation of infectious aerosols. Some safe cleaning techniques include wet mopping of the floor with disinfectants or spraying the floor with a disinfectant or water before sweeping it. For larger areas, such as industrial hatching chambers, low-pressure washers instead of highpressure cleaners are strongly recommended.

\section{Conclusions}

Until now, in ovo transmission of C. psittaci has been considered of minimal impact. In the present study, we found increasing amounts of $C$. psittaci in the air during hatching of turkeys or chickens. Thus, hatchlings could already be infected before arriving on the farm. Diagnostic monitoring and reporting of C. psittaci infections in poultry workers should be promoted. Additionally, an efficient veterinary vaccine and information campaigns on zoonotic risk and preventive measures against $C$. psittaci transmission would be beneficial to public health.

\section{ACKNOWLEDGEMENTS}

This study was funded by the Federal Public Service of Health, Food Chain Safety and Environment (convention RF-6177).

\section{REFERENCES}

Beeckman, D. S. \& Vanrompay, D. C. (2009). Zoonotic Chlamydophila psittaci infections from a clinical perspective. Clin Microbiol Infect 15, 11-17.

Chahota, R., Katoch, R. C., Singh, S. P., Verma, S. \& Mahajan, A. (2000). Concurrent outbreak of chlamydiosis and aflatoxicosis among chickens in Himachal Pradesh, India. Veterinarski Arhiv 70, 207-213.

Cox, N. A., Berrang, M. E. \& Cason, J. A. (2000). Salmonella penetration of egg shells and proliferation in broiler hatching eggs $-\mathrm{a}$ review. Poult Sci 79, 1571-1574.

Dickx, V., Geens, T., Deschuyffeleer, T., Tyberghien, L., Harkinezhad, T., Beeckman, D. S., Braeckman, L. \& Vanrompay, D. (2010). Chlamydophila psittaci zoonotic risk assessment in a chicken and turkey slaughterhouse. J Clin Microbiol 48, 3244-3250.

Gaede, W., Reckling, K. F., Dresenkamp, B., Kenklies, S., Schubert, E., Noack, U., Irmscher, H. M., Ludwig, C., Hotzel, H. \& Sachse, K. (2008).
Chlamydophila psittaci infections in humans during an outbreak of psittacosis from poultry in Germany. Zoonoses Public Health 55, 184188.

Geens, T., Dewitte, A., Boon, N. \& Vanrompay, D. (2005). Development of a Chlamydophila psittaci species-specific and genotype-specific real-time PCR. Vet Res 36, 787-797.

Harkinezhad, T., Geens, T. \& Vanrompay, D. (2009). Chlamydophila psittaci infections in birds: a review with emphasis on zoonotic consequences. Vet Microbiol 135, 68-77.

HSE (2010). Infection at work: controlling the risks. A guide for employers and the self employed on identifying, assessing and controlling the risks of infection in the workplace. Advisory Committee on Dangerous Pathogens.

Laroucau, K., de Barbeyrac, B., Vorimore, F., Clerc, M., Bertin, C., Harkinezhad, T., Verminnen, K., Obeniche, F., Capek, I. \& other authors (2009a). Chlamydial infections in duck farms associated with human cases of psittacosis in France. Vet Microbiol 135, 82-89.

Laroucau, K., Vorimore, F., Aaziz, R., Berndt, A., Schubert, E. \& Sachse, K. (2009b). Isolation of a new chlamydial agent from infected domestic poultry coincided with cases of atypical pneumonia among slaughterhouse workers in France. Infect Genet Evol 9, 12401247.

Lublin, A., Shudari, G., Mechani, S. \& Weisman, Y. (1996). Egg transmission of Chlamydia psittaci in turkeys. Vet Rec 139, 300.

Mayr, A., Bachmann, P. A., Bibrack, B. \& Wittmann, G. (1974). Virologische Arbeitsmethoden. Jena: Gustav Fischer Verlag.

Sting, R., Lerke, E., Hotzel, H., Jodas, S., Popp, C. \& Hafez, H. M. (2006). [Comparative studies on detection of Chlamydophila psittaci and Chlamydophila abortus in meat turkey flocks using cell culture, ELISA, and PCR]. Dtsch Tierarztl Wochenschr 113, 50-54 (in German).

Van Droogenbroeck, C. M., Van Risseghem, M., Braeckman, L. \& Vanrompay, D. (2009a). Evaluation of bioaerosol sampling techniques for the detection of Chlamydophila psittaci in contaminated air. Vet Microbiol 135, 31-37.

Van Droogenbroeck, C., Beeckman, D. S., Verminnen, K., Marien, M., Nauwynck, H., Boesinghe, L. T. \& Vanrompay, D. (2009b). Simultaneous zoonotic transmission of Chlamydophila psittaci genotypes D, F and E/B to a veterinary scientist. Vet Microbiol 135, 7881.

Van Loock, M., Geens, T., De Smit, L., Nauwynck, H., Van Empel, P., Naylor, C., Hafez, H. M., Goddeeris, B. M. \& Vanrompay, D. (2005a). Key role of Chlamydophila psittaci on Belgian turkey farms in association with other respiratory pathogens. Vet Microbiol 107, 91101.

Van Loock, M., Verminnen, K., Messmer, T. O., Volckaert, G., Goddeeris, B. M. \& Vanrompay, D. (2005b). Use of a nested PCRenzyme immunoassay with an internal control to detect Chlamydophila psittaci in turkeys. BMC Infect Dis 5, 76.

Vanrompay, D., Ducatelle, R. \& Haesebrouck, F. (1992). Diagnosis of avian chlamydiosis: specificity of the modified Giménez staining on smears and comparison of the sensitivity of isolation in eggs and three different cell cultures. Zentralbl Veterinarmed B 39, 105112.

Vanrompay, D., Van Nerom, A., Ducatelle, R. \& Haesebrouck, F. (1994). Evaluation of five immunoassays for detection of Chlamydia psittaci in cloacal and conjunctival specimens from turkeys. J Clin Microbiol 32, 1470-1474.

Vanrompay, D., Ducatelle, R. \& Haesebrouck, F. (1995a). Chlamydia psittaci infections: a review with emphasis on avian chlamydiosis. Vet Microbiol 45, 93-119. 
Vanrompay, D., Mast, J., Ducatelle, R., Haesebrouck, F. \& Goddeeris, B. (1995b). Chlamydia psittaci in turkeys: pathogenesis of infections in avian serovars A, B and D. Vet Microbiol 47, 245-256.

Verminnen, K., Van Loock, M., Hafez, H. M., Ducatelle, R., Haesebrouck, F. \& Vanrompay, D. (2006). Evaluation of a recombinant enzyme-linked immunosorbent assay for detecting Chlamydophila psittaci antibodies in turkey sera. Vet Res 37, 623-632.
Verminnen, K., Duquenne, B., De Keukeleire, D., Duim, B., Pannekoek, Y., Braeckman, L. \& Vanrompay, D. (2008). Evaluation of a Chlamydophila psittaci infection diagnostic platform for zoonotic risk assessment. J Clin Microbiol 46, 281-285.

Wittenbrink, M. M., Mrozek, M. \& Bisping, W. (1993). Isolation of Chlamydia psittaci from a chicken egg: evidence of egg transmission. Zentralbl Veterinarmed B 40, 451-452. 